\title{
Old Age Protection in the Context of Rural Development
}

\author{
Xiaomei Pei and Youcai Tang
}

\begin{abstract}
This study examines the potential of rural communities for generating and allocating resources for rural old age support in the context of decreasing family resources and inadequate state provision. In-depth interviews with elderly people, their families, community leaders and government officials of three villages, respectively located in three provinces provide us with clear evidence on existing local institutional arrangements for rural old age support and the role of both government and community in organising such programmes. They confirm the potential of rural communities to generate and distribute resources for old age support, offering community opportunities for social inclusion through fair flows of resources to promote social harmony and stability, and accelerating economic growth. The findings of the study imply that there is a need for policymakers to link the state effort for old age protection to rural community development, and encourage grassroots efforts in old age support.
\end{abstract}

\begin{abstract}
1 Introduction
The social organisation of support for rural aged people in societies undergoing rapid social transition has proven to be problematic not only because of a lack of political interest among policymakers, but also because of insufficient understanding of the needs of older rural residents and the absence of effective mechanisms for sustainable resource allocation. While state initiatives on social pensions may provide an alternative for organising social protection for the rural aged population, their need for support can hardly be adequately addressed without the fair distribution of local resources.

China illustrates the difficulty of providing social protection for the rural aged population often found in developing societies. China, having experienced tremendous demographic transition, indicated by a rapid increase in the number of the aged since the 1980s, the total number of those aged 60 and above has reached 169 million, making this group 12.79 per cent of the total population by the end of 2008 (State Bureau of Statistics 2009). Of the elderly in China, nearly 70 per cent currently reside in rural areas and very few of them are covered by existing state old age insurance programmes
\end{abstract}

(Xinhua News Agency 2009). At the same time, rural communities in China have experienced profound social and economic transition during which family resources for old age support have been substantially undermined.

A national survey in 2005 indicated that, despite the existence of a national and some local social insurance programmes, the distribution of insurance coverage among the Chinese elderly is geographically uneven. In urban areas, 57.5 per cent of the elderly are covered by old age insurance or retirement pensions, while in township areas, the proportion covered is 24.8 per cent; and beneficiaries in rural areas make up only 4.6 per cent of the rural aged. At present, 54.1 per cent of the rural aged Chinese have to rely on family and 37.9 per cent of them still work to support themselves (State Bureau of Statistics 2005).

The Chinese government tried to organise an old age insurance programme for the rural elderly at county level in the early 1990s. However, a lack of stable income was a barrier to farmers' continued contributions. As a result, a very limited number of such programmes in rural areas have been sustained through the rapid

IDS Bulletin Volume 41 Number 4 July 2010 @ 2010 The Authors. Journal compilation (c) Institute of Development Studies Published by Blackwell Publishing Ltd, 9600 Garsington Road, Oxford OX4 2DQ, UK and 350 Main Street, Malden, MA 02148, USA 
industrial transition. By the end of 2000, only 61 million rural people, 11 per cent of the rural population, were still participating. The number of elderly benefiting from this insurance was even smaller, and the average level of yearly benefits from the insurance was even lower than that received from social relief programmes for people in poverty. As a result, the programme reached stagnation at the beginning of the new century (Ding and Chen 2005).

Some reasons have been identified for the failure of this rural old age insurance programme. First, it was based on the idea of commercial insurance where a flat rate contribution from individual peasants was expected. However, farmers did not receive as stable an income as urban workers. Moreover, their income was so low that they had difficulty finding extra money to contribute to the old age insurance fund. Even if they joined the programme, they tended to keep the insurance at the minimum level. Second, the programme was organised so that only those who were wealthier and younger could be included and those who were relatively poor and older tended to be excluded. Third, even in some places where farmers could make contributions, there was a lack of experience among programme organisers in managing the funds and problems of inappropriate fund management were widespread. Last but not least was the lack of a legislative basis for organising such a programme, which led to competition among government sectors for control over funds without effective systems for monitoring (Qiao 1998; Gao 2003; Huang 2004).

Leaving these problems unresolved, the Chinese government has recently made an effort to establish a national social pension funded by public finance, in response to the need of the rural aged population for income protection. The scheme was piloted in 2009 and was expected to launch in 2010. The scheme provides rural residents aged 60 and above with a monthly income of 55 yuan, which is financed directly from the state. It is still early to evaluate the impact of such a scheme on the rural aged Chinese. Existing studies (Barrientos 2005; HelpAge International 2006; Johnson and Williamson 2006; Samson, Niekerk and MacQuene 2006) on the practice of social pension schemes in some developing countries seem to uniformly confirm the positive impact of such programmes on poverty reduction among the aged. National public opinion also regards the scheme as a positive step towards institutionalised rural old age security. On the other hand, the uniformly low rate of benefits makes it reasonable to question the programme's adequacy. Its limitations are obvious, and there is an increasing public awareness of the importance of a fair redistribution of resources at local and community level to supplement the state's efforts.

The encouragement of the involvement of old people and organisations in the community becomes increasingly critical for the effectiveness and sustainability of any programme of support. In searching for potential mechanisms for rural community involvement in the organisation of support for the elderly, there is a need to understand the local institutional and cultural environment, how community resources are mobilised and distributed, the relationship between various stakeholders in the community and the operation of existing community programmes for old age protection. This study of three cases of rural aged support practice, based on different geographic locations in China, generates first-hand knowledge about the reality of rural old age protection in transitional China, and enhances our understanding of the above questions.

\section{Methodology}

This exploratory study used qualitative methods of field observation and in-depth interviews with community residents to collect information on the daily lives of old villagers and their living environment, principles and mechanism of community resource mobilisation and distribution, and the organisation of community efforts for old age support. The selection of villages was purposeful, taking into account various levels of development. Among the three villages chosen, one is a case located in a more economically developed area where community life remains relatively collective. The second is located in a region where the level of development is about the national average, and the third case is located in a region that is relatively underdeveloped. As China has a large territory and is so geographically diverse, instead of random sampling, we selected cases to represent different conditions as a result of different levels of socioeconomic development of different regions. We are fully aware of the limits of the method used and limited our 


\begin{tabular}{|c|c|c|c|}
\hline \multirow[t]{2}{*}{ Characteristics } & \multicolumn{3}{|c|}{ Village } \\
\hline & $J X$ & DZT & ZZ \\
\hline Villagers aged 60 and over & $\begin{array}{l}142(17 \% \text { of the total } \\
\text { population of } 822)\end{array}$ & $\begin{array}{l}479(18 \% \text { of the total } \\
\text { population of } 2,668)\end{array}$ & $\begin{array}{l}166(9 \% \text { of the total } \\
\text { population of } 1,524)\end{array}$ \\
\hline Living arrangement & $\begin{array}{l}\text { Almost all live } \\
\text { independently }\end{array}$ & Most independently & $\begin{array}{l}\text { Some independently; some } \\
\text { with children }\end{array}$ \\
\hline Income & $\begin{array}{l}\text { Stable and multiple } \\
\text { sources }\end{array}$ & $\begin{array}{l}\text { Less stable but multiple } \\
\text { sources }\end{array}$ & $\begin{array}{l}\text { Unstable and limited } \\
\text { sources }\end{array}$ \\
\hline Labour participation & $\begin{array}{l}\text { General participation in } \\
\text { paid labour }\end{array}$ & $\begin{array}{l}\text { General participation in } \\
\text { paid labour }\end{array}$ & $\begin{array}{l}\text { General participation in } \\
\text { agricultural labour }\end{array}$ \\
\hline
\end{tabular}

understanding of the information collected to the generation of the meaningful questions about rural aged support, rather than making any generalisations.

Our research team went to three study villages (referred to here as villages JX, DZT and ZZ) to conduct field research, three times between July, 2008 and May, 2009. First-hand information was gathered through field observations, in-depth interviews and focus group discussions. Content and textual analysis of the information collected allowed us to understand the channels through which community resources flow to individual elderly persons; the effects of the flows on individual and households; the relations of flows to community development; and the economic and social positions of the elderly in the family and community.

\subsection{The status of the aged in the three study villages} Although over half of the Chinese still live in rural areas, it is very difficult to make generalisations about their living standards because huge gaps exist between those who live in relatively developed areas and those in underdeveloped areas; between those who live along coastal areas in the east; and those who live inland in the west. These differences are also reflected in the status of the elderly. We can see from Table 1 that demographic differences among the three cases are obvious. While the elderly make up 17 per cent of the total population in JX village and 18 per cent in DZT village, respectively, the same age group only makes up 9 per cent in $\mathrm{ZZ}$ village. Another obvious difference is in income status. In JX village, all the aged villagers are covered by local and community old age insurance programmes. However, the majority of the aged in DZT and $\mathrm{ZZ}$ villages are not protected by any old age insurance programmes. In the absence of a stable income from social security, old people in these two villages have to rely on income generated from work if they are capable, along with cash and in-kind provision from adult children. In DZT village there were well organised paid labour opportunities for the old and subsidies were provided by the village's Association for Old Persons, to those in poverty. In $\mathrm{ZZ}$ village, there were no organised efforts to support the aged.

This study found that children's resources for supporting their aged parents were limited. They usually had no problem providing food, clothes and daily necessities to the aged parents in need of support. However, providing cash to pay for their parents' medical bills and for their social activities could become difficult to sustain (Tang and $\mathrm{Xu}$, forthcoming). This finding is confirmed by the survey of the New Cooperative Medical Scheme in rural China (NCMS) (another SPA project), which found that even with the NCMS in place, about 20 per cent of the elderly had to pay their bills out of pocket and nearly 38 per cent of them had the NCMS reimburse only small proportions of the bills. Reimbursement rates declined along with the increase in expenditures (Yi and Zhang 2009).

Despite these differences in the proportion of the aged and their income status, old persons across the three villages shared similarities in living arrangements and labour participation. Contrary to beliefs regarding the rural living 


\begin{tabular}{|c|c|c|c|}
\hline \multirow[t]{2}{*}{ Support } & \multicolumn{3}{|c|}{ Village } \\
\hline & $J X$ & DZT & ZZ \\
\hline Provisions & $\begin{array}{l}\text { Pension/housing/job } \\
\text { opportunities/medical } \\
\text { care/LTC subsidy }\end{array}$ & $\begin{array}{l}\text { Paid job opportunities/ } \\
\text { living subsidies }\end{array}$ & $\begin{array}{l}\text { Occasional subsidies for } \\
\text { organised entertainment } \\
\text { activities }\end{array}$ \\
\hline Coverage & All members & $\begin{array}{l}\text { Those physically capable; } \\
\text { those in poverty }\end{array}$ & Those socially active \\
\hline Funding & $\begin{array}{l}\text { Budget by village } \\
\text { committee }\end{array}$ & $\begin{array}{l}\text { Budget by Association for } \\
\text { Old Persons }\end{array}$ & No budget \\
\hline Community resources & $\begin{array}{l}\text { Profits from village-owned } \\
\text { industrial output }\end{array}$ & $\begin{array}{l}\text { Profits from collectively } \\
\text { owned and NGO- } \\
\text { managed businesses }\end{array}$ & $\begin{array}{l}\text { Profits from farmland } \\
\text { leasing }\end{array}$ \\
\hline
\end{tabular}

arrangements of old people with large families, the elderly in these three villages tended to live in a separate household from their adult children. Moreover, whether they were protected by income maintenance programmes or not, they tended to participate in productive labour as long as they were physically capable.

\section{Review of the communities studied}

The three communities in this study vary in terms of size and resources for old age provision. Table 2 demonstrates their variations in community provision, coverage, funding and resources generation for old age support. A review of the development of each case in the following section is intended to provide a contextual background.

\subsection{Integrating old age provision into community development: the case of JX village}

$J X$ village was located in an area where the manufacturing industry had been rapidly developed in the past three decades. It was a village of 822 residents, 142 of them aged 60 and over. In the past three decades, the village quickly accumulated some collective resources through the successful organisation and operation of four collectively owned enterprises. In 2008, the village's total GDP was 2 hundred million yuan, the average income per capita was 19.3 thousand yuan, and the total income of the village was 10 million yuan.

With the funds generated from industrial production, the community leader and his decision-making group developed a collective welfare system that ensured a secure later life for villagers. The village welfare provisions for the aged included: pension income, free medical care, free retirement apartments with furniture, subsidies for families caring for frail elderly members and opportunities for paid work. Villagers started to benefit from these village provisions at the age of 55 . The elderly had a monthly pension income of 300-600 yuan according to age. They could choose to live with children or independently in an apartment in the retirement housing area, which was located within the same village. If they were healthy and willing to do some work, they would have the opportunity to get a paid job as a gardener, a street cleaner, or cafeteria helper. If they were sick, they could get free medical care at a village clinic and reimbursement for medical expenses on hospital visits.

The case of JX village seems to confirm again the argument that the community provisions for old age support only happen where substantial resources are accumulated through economic development. However, a further examination of the history of the village showed that the development of community old age provisions started long before the resources were accumulated. In the early 1980s when the village's resources were very limited, the community leaders prioritised pension provision to aged community members in their development agenda. At that time, they believed that this was the right approach to the implementation of state policy on family planning. Unlike most of the rural villages in the area, where land and other community resources 
were privatised, JX village had maintained collective production and organisation. At first, the pension benefit level was small and coverage was relatively low. With economic growth and an increase in the amount of resources had come the gradual rise of pension benefit levels and the expansion of old age welfare coverage. This was based on the prioritisation of fair sharing of the products of economic growth among the villagers. In 2007, community expenditure on pension payments only reached 611,400 yuan, about 6 per cent of the total collective income that year.

The development of welfare provisions for the aged in JX village as part of the village development benefited from the political determination of the community leaders to ensure 'wealth for all' played a critical role in constructing community welfare programmes. Since the 1980s the village leader, a charismatic figure, has persistently held a belief in collective ownership of the land and other production materials as an approach to collective prosperity. Under his leadership, the village experienced rapid growth in industrial and agricultural production and a fair distribution of the wealth accumulated through economic development. As a result of this welfare provision, the distribution of income and material resources among villagers was relatively even.

The case also demonstrated a coordination of government and community support. As mentioned above, the village is located in a relatively welldeveloped area compared with other parts of the country. In 1992, the local government started to organise a pension programme for farmers, funded by insurance contributions from farmers and subsidies by the local government. The pension from the old age insurance provided elderly people with an income that was stable but relatively small. The organisation of the community pension provision in JX funded by resources generated from collective production, effectively supplemented the local government insurance programmes. As a result, the individual income of the aged persons in JX was substantially higher than that of the aged in the surrounding villages, which enabled them to maintain an independent status in their community and families. When the state rural medical insurance programme started in 2006, the contribution of the individual villagers to the medical insurance was paid by the collective fund.

\subsection{Empowering the elderly through community organisation: the case of DZT village}

The case of DZT illustrates a self-organised effort by elderly community members to create resources for community welfare provisions as part of their effort to contributing to the economic growth of the village. The village had a population of 2,668 people and the average income of the villagers in 2008 was 7,506 yuan, 20 per cent higher than the average in the surrounding villages. Farmers there were generally involved in vegetable growing and generated income mainly from selling vegetables and other farm products. As a result, their income level had remained low and the community had very limited resources for old age support. Unlike other villages nearby, DZT had a senior organisation, the Association for Old Persons (AOP), searching for opportunities for older villagers to live independently while contributing substantially to local economic development. The AOP was initiated and led by a group of people who had retired either from teaching or from commercial institutions in 1992. The original purpose for establishing such an association was to manage and regulate the village-based wholesale vegetable market. After 16 years of development, the market became one of the largest vegetable trading centres, providing commercial services to a population of over 100,000 vegetable growers from about 1,000 villages in the region. The market also created about 1,400 jobs for local people and an elderly person who was willing and physically capable in the village usually had an opportunity for a paid job.

The market became the major source of income for the community. Along with the development of the market, the AOP generated funds for starting up 13 service business entities, such as vegetable storage, oil supply, inns and restaurants, two trial programmes for vegetable growers - vegetable planting and tropical fruit growing demonstrations - and three workfare programmes, particularly for old people involved in gardening, freshwater aquiculture and courtyard production. By 2008, this selforganised association had accumulated assets of over 10 million yuan, paid a total tax of 17 million yuan to the state and contributed over 5 million yuan to the village collective. In 2008 alone, AOP generated an income of 12.98 million yuan. 
Older people in DZT benefited from the efforts of the AOP in terms of opportunities for flexible employment and related income, which enhanced their ability to be financially independent and secure. They also benefited from the village welfare programmes funded by an increasingly sound collective income source. These programmes include collective contributions to the state rural medical insurance for all the villagers, welfare subsidy provision to AOP's 528 members (including elderly people in the surrounding villages), the operation of the old age school and the senior centre. In general, the AOP acts as a significant resource for community old age support and other welfare provisions.

The overall increase in villagers' living standards and the specific empowerment of the elderly through organised efforts has led to changes in intergenerational relationships in village families. A villager manager described the gradual formation of a more positive intergenerational relationship within families since the 1990s. It has been noted that many elderly people still lived together with one of their adult children. However, more and more old people chose, and were able, to live independently of their children in a separate household. Like the elderly living in old age apartments in JX, this independent living arrangement promoted more positive interaction between generations, since it enables the elderly to relate to their children on a more equal basis.

In DZT, we see how old people can be empowered to maintain an independent life, how a community can develop with the resources contributed by its older members, and how the aged can benefit from their community. In the absence of pension coverage for the majority of elderly villagers, grassroots efforts to mobilise collective resources for old age support by the aged themselves appear to be especially valuable and effective.

\subsection{Creating an opportunity for independence: the case of $\mathrm{ZZ}$ village}

The case of $Z Z$ village presents a less organised effort by the rural elderly and lack of community incentives for old age provision. Here, individual efforts were made to seek opportunities for economic independence and living autonomy. ZZ is located along the Yellow River, an area much less developed than coastal areas. Currently, its main economic output comes from agricultural produce, specifically asparagus and apples. The area was the largest base for asparagus growing in China and had eight asparagus processing businesses. This village has a population of 1,524 people, with an average income of 4,000 yuan in 2008. It has very limited community welfare provision. About 60 per cent of the elderly live separately from their adult children and family support is also limited. The elderly generally make a living by working in the fields as long as they are able.

The unique phenomenon about $\mathrm{ZZ}$ was the selection of some aged villagers who lived and laboured on the beach of the Yellow River about three miles from the village. Encouraged by local policy, some villagers started to cultivate the land on the beach in the 1980s. The land was productive and income was better than working on the land in the village. They built houses on the beach and lived there for over two decades. We noticed at the time of the study that these villagers were between the ages of 63 and 80 . The elderly on the beach believed that the beach was a more appropriate place for them to live. They said the air was cleaner and the water softer in comparison with the village. They lived in very modest houses of 20-30 square metres with two or three furnished rooms. Some had a television. The houses tended to be surrounded by the cultivated land or orchards. All the old people living on the beach had remained physically and functionally independent. While living independently in their own houses, they have formed a neighbourhood that allows for close communication.

Not all the village elderly lived on the beach. About two-thirds still lived inside the village and the majority of them were actively involved in farming production, including 25 people aged 80 and over. As the income generated from agricultural production was unstable, the elderly villagers were living very modestly. Old couples tended to live independently in a house of their own. Those who had lost a spouse tended to continue living independently or with one of their children, depending on whether there were adult children in the village and depending on their own financial situation and that of their children. Some older people had to rely on their children for a living when they were no longer 
able to work. There were still problems for those who did not have any income, who were too old to work or whose children were not in a financially sound situation. Many of these people were elderly women. Even if they lived under the same roof, they tended to be neglected by other members of their family.

Community organisations such as the village's Association for Old Persons, limited their role to mediating in family conflicts and liaising between individuals who were in need of help and the village administration.

\section{Findings}

The three cases above provide us with a partial picture of old age support in rural China. With variation in terms of geography, history and level of development, the three cases show a clear tendency of independent living among aged persons. A growing number of elderly choose to live separately from their children when they have a stable income of their own, most likely when income could be maintained from social insurance programmes. But this separate living within the community does not disengage the old people from their families. On the contrary, it gives both the elderly and the younger generation more free space and more equal status, promoting harmonious generational interaction. Although social security provisions from the state and the local governments are critical to ensure independence for the elderly, the community's role is also important in enhancing their independence through generating and distributing resources, organising welfare benefit delivery, creating opportunities for social and economic participation, and coordinating state and local efforts.

Some evidence for the potential of communities has been identified from the case studies above. First of all, we see clearly that grassroots organisations with trusted leadership are crucial for community old age provisions. Both JX and DZT villages provide evidence for the impact of organised efforts on community welfare provisions. While JX relied heavily on a formal administrative organisation in building a community welfare system, DZT was found to have an organisation run by old people themselves. Both organisations worked effectively under leadership that was generally trusted by community members, and that was coherent so that organisational efforts could be sustained for a relatively long time. In contrast, a lack of organised old age provision in ZZ has been found to be closely related to the dysfunction of the village administrative body as a result of distrust among the villagers. The comparison between these cases makes clear the important role of effective community organisations in mobilising resources for old age provision.

Second, we have found a positive relationship between community old age provision and community development in JX and DZT villages, which proved that resources for old age provisions can be created and mobilised in communities where organisational efforts have been made. The two villages started to work on community welfare provisions when community resources were still very limited, in the early 1980s and 1990s, respectively. The collective provisions for the elderly have been seen by village leaders as part of community development and as a way to share the products of growth. When old age provisions are put on the community development agenda, it is in the context of the accumulation of community resources. The impact of the old age provisions on community development has been found in active involvement and contribution of the protected aged persons to the economic activities as valuable human resources. Thus, a positive interaction between the elderly and the community has been formed. In the case of ZZ, we see the opposite occurring: where there is a lack of community protection for the aged, there is also an absence of organised efforts for community development.

Third, a comparison of the three cases has led us to see that the fair distribution of community resources is more important than the amount of resources available in the development of community provisions for the aged. In fact, it is not difficult to find wealthy communities in contemporary China without social provision for the aged. Obviously the availability of resources does not necessarily lead to these provisions. The cases studied here have identified community values regarding distribution as an important variable in old age provision. We see in JX a principle of sharing in resource distribution. One of the community leaders said: 'funds are always limited and there are always many places where funds are requested. We need to prioritise enough funds for the most vulnerable and the aged 
persons are among them'. In DZT, we also see that the contribution of the aged to the economic growth of the village has been well recognised and such recognition justifies the community's efforts regarding old age provisions. In comparison, the absence of shared values for fair distribution and negligence toward the aged among community members has been found in ZZ.

Fourth, we have found that the aged are a valuable resource for rural development in general and for community old age provision in particular. We see in JX village the active involvement of aged villagers in various productive positions and community political activities. In DZT, major economic entities have been developed and managed by the aged under the leadership of the Association for Old Persons. These village enterprises generated tremendous interest in the village collective and created job opportunities for both the community members and the people from surrounding communities. Along with the community development is the expansion of old age provision. In fact, we see here that old age support has been provided by the aged community members themselves. Instead of being a burden, the elderly are valuable contributors to community building. Even in the case of ZZ, where few organised efforts have been made, many individual elderly maintain a productive life. It seems that if effectively organised, these individual efforts could become a force in collective development.

Finally, evidence has been found that integration of community old age provisions with state and local government efforts appears to be effective in meeting the needs of the rural aged. We see that in the area where JX is located, the local government started in 1992 to implement an old age insurance programme for the local elderly. Nevertheless, the benefit level has been too low for beneficiaries to maintain a basic living. The provision of community pensions in JX effectively addresses the inadequacy of the local programme as an important supplement. A sense of security among the elderly villagers has increased along with their sources of income. In DZT, we see an active coordination between the Association for Old Persons and the related district government offices, which leads to collaborative efforts of the community and the local government in building a nursing facility for those aged who need care.
This study of three rural communities in contemporary China provides some clear evidence on the potential of community organisations in delivering social support for aged community members. The realisation of this potential is conditioned not only by availability of collective resources, but also by shared principles on resource distribution and leadership for organisation. In this sense, communities are having an increasing impact on local welfare provisions.

At the same time, we also see some limits to community efforts. There is generally a lack of an institutional basis for old age provision even in communities where current provisions are relatively comprehensive. Where community decisions on old age provision rely heavily on charismatic leadership rather than on institutional procedures, it is justifiable to question the sustainability of these provisions.

\section{Policy implications}

This discussion about the role of the community in support for the rural aged has important implications for rural policy development in China. First of all, rural communities are as active as the state in searching for ways to meet the challenge of old age support and local efforts predate state action. The experience accumulated by some rural communities is extremely valuable to state and local governments in building welfare for the aged. To meet the growing support needs of the rural aged, the state should incorporate community organised efforts into its plans. As mentioned previously, the state social pension programme is expected to extend coverage to all the aged in rural China by the end of 2010. The monthly income of 55 yuan for an elderly person would be very helpful but not enough to maintain a decent living in many areas in China.

Community provisions would not only provide the aged person with more sources of income, but also serve as supplements to share the responsibilities with the state.

The second implication for state policymaking is the importance of resource distribution revealed by our study. Recent decades witnessed a rapid accumulation of resources by the state, along with rapid economic growth. If fair distribution can occur at the community level, it should also be possible at the state level. Obviously the policy issue should be one of distributive justice, 
rather than that of the availability of resources. Finally, the findings of this study also echo the argument for the importance of welfare provisions as an integrated part of rural development (Hall and Midgley 2004). Policymakers should seriously consider an institutional frame for community old age provision matching the continuing development of the community so that community provisions could not only be developed but also sustained.

The findings from this study also have implications for other developing societies undergoing rapid demographic transition. It is well known that old age support as a policy issue has increasingly attracted public attention in contemporary societies as a result of the rapid ageing of many societies. However, the issue

\section{References}

Barrientos, Armando (2005) 'Non-contributory Pension and Poverty Reduction in Brazil and South Africa', mimeo, Manchester: Institute for Development Policy and Management (IDPM), University of Manchester

Ding, Shijun and Chen, Chuanbo (2005) Security for the Aged in Rural China During the Economic Transitional Period of Time, Beijing: China Finance and Economics Press

Gao, Herong (2003) 'Why the Project "Social Supporting for Elderly in County Level" does not Work in Rural China', Market and Demography Analysis 9: 17-21

Hall, Anthony and Midgley, James (2004) Social Policy for Development, London: Sage Publications

HelpAge International (2006) 'Why Social Pensions are Needed Now', HelpAge International Briefing Paper, www.helpage.org/ Researchandpolicy/PensionWatch/Feasibility

Huang, Xiaoli (2004) 'Rural Aged Insurance: Problems and Strategies', Journal of Shayang Teachers College 6: 59-62

Johnson, Jessica, K. and Williamson, John, B. (2006) 'Do Universal Non-contributory Oldage Pensions Make Sense for Rural Areas in Low-income Countries?', International Social Security Review 59.4: 47-65

Qiao, Xiaochun (1998) 'An Analysis of Social Support Insurance System for the Rural Aged in China', Demographic Research 5: 8-13 presents different challenges for developed and less developed societies. While in the former the old are usually covered by relatively

comprehensive social security programmes, the majority of the aged in developing societies still rely on family resources which are significantly undermined by economic transitions locally as well as globally. While social pensions offered in some of the transitional societies are viewed as an effective way to address the need for old age support, relative low levels of benefits and sustainability of funding are always issues in the adequacy of such provisions. If this evidence from community organised efforts in rural China can offer any suggestions for policy development for old age provision in developing countries, it is that they can form a relatively effective and supplemental approach to government actions.

Samson, Michael; van Niekerk, Ingrid and MacQuene, Kenneth (2006) Designing and Implementing Social Transfer Programmes, Cape Town, South Africa: EPRI Press

State Bureau of Statistics of the People's Republic China (2009) China Population Statistics Yearbook 2009, Beijing: China Statistics Press

State Bureau of Statistics of the People's Republic China (2005) National Survey on a Sample of $1 \%$ of the Total Population, Beijing: China Statistics Press

Tang, Youcai and $\mathrm{Xu}$, Xiaofeng (forthcoming) 'Factors Affect Intergenerational Relations in Rural Aged Households in Contemporary China: An Empirical Analysis', accepted for publication by Population and Economics

Xinhua News Net (2009) Unexpected Speed of Population Aging in China, 26 October, http://news.xinhuanet.com/politics/200910/26/content_12331024.htm

Yi, Hongmei and Zhang, Linxiu (2009) 'Good News, Bad News: Results from a National Representative Panel Survey on China's NCMS', SPA Working Papers, paper presented at SPA Program working meeting at the Hanoi, Vietnam, 2 June 2009 